\title{
McKay, Sandra and Nancy H Hornberger (Eds). Sociolinguistics and Language Teaching. pp 484. Cambridge: Cambridge University Press.
}

Teachers (both those doing pre-service education and those doing in-service education) will welcome the publication of this book. It provides an accessible overview of the central issues in sociolinguistics, with the primary focus falling on the relationship between language acquisition and the social context of language. It also deals extensively with language variety within languages (of particular interest to teachers of English) and the ways they are influenced by factors such as race, class, and gender differences. The book also provides a clear account of issues such as literacy and world varieties (including the term 'standard'). Of perhaps the most value to teachers, however, is the focus on the nature and needs of multilingual and multicultural classes.

The contributors have been clearly chosen for their knowledge of a particular topic as well as of the particular needs of the classroom teacher. Each of the fourteen chapters draws extensively on research in giving a coherent account of a particular topic, and concludes with clear implications for the classroom. A generous list of suggestions for further reading is provided.

The book is arranged in four parts. In Part One entitled "Language and Society", four issues are addressed: Language, Attitudes, Motivations and Standards (Mary McGroarty), Societal Multilingualism (Kamal Sridhar), World Englishes (Braj Kahru and Cecil Nelson) and Language Policy (Terrence Wiley). In Part Two, "Language and Variation", Regional and Social Variation (John Rickford), Pidgins and Creoles (Patricia Nichols) and Language and Gender (Rebecca Freeman and Bonnie McElhinny) are addressed. Part Three, "Language and Interaction", explores and explains forms of sociolinguistic analysis: Ethnographic Microanalysis (Frederick Erikson), Interactional Sociolinguistics (Deborah Schriffin) and Intercultural Communication (Keith Chick). Part Four, "Language and Culture", includes Sandra McKay's particularly accessible discussion of literacy as well as Andrew Cohen's discussion of speech acts.

Nancy Hornberger does a good job of drawing the threads together and suggesting future areas of concern in her concluding chapter.

Practising teachers in South Africa, will find immediate interest and value in the first two chapters. The first chapter, for instance, makes possible an understanding of the complex relationship between linguistic attitudes (teacher's, learners' and parents') and the learning process, on the one hand, and standards, on the other. This should make teachers better equipped to create the conditions in their classrooms which will enable learners to develop the skills necessary for effective participation. 
The second chapter provides a careful description of multilingualism, which includes clear definition of terms such as bilingualism as opposed to multilingualism. In terms of the current concerns in South Africa, two issues are of especial interest. The first is the case that is made for teachers in a multilingual situation to value bilingualism. The second is the call for language goals and standards to be established in the light of broader social and political criteria.

In Part 2, Rickfords gives a fascinating account of the development of dialectal features. Of particular interest is the discussion of the major phonological and syntactic features of African and American Vernacular English. In South Africa, the classroom implications of Black English are just beginning to be recognised. At the very least, dialect provides a rich resource within the classroom, which should be used to develop literacy skills and to enhance individual and social identities.

The last chapter in this section (Language and Gender) relates very closely to the concerns of OBE. Here the focus is on recognising the ways in which gender bias is reflected in language, so that it may not continue to be a subtle but effective means of reinforcing subordinate (or rigid) roles. Teachers are challenged to find ways of challenging inequities through the use of alternate language. Practical suggestions in this chapter include the use of material that represents social identity groups more equally, and the manipulation of group dynamics in the classroom so that all leamers have the opportunity to participate strongly.

Part 3 is concerned with microlevel social and linguistic analysis. Apart from the chapter by Keith Chick (Intercultural Communication), this part is considerably less accessible than the rest of the book. It seems rather too complex for an introductory text.

Chick's chapter will be of especial interest to South African teachers. Making intercultural communication more effective is of vital importance in this country. Chick makes a valuable contribution in highlighting the importance of not presenting conventions as neutral practices. He does make some practical suggestions, but far more applied work remains to be done. His challenge is a bold one:

... leamers need information not only about sociolinguistic variation but also what is at stake. They need to know that, although they may be able to avoid being misevaluated by gatekeepers by making accommodations to their sociolinguistic norms, there is a cost. Not only is there a risk that these conventions may assign them social identities with which they are uncomfortable, but their compliance will further legitimize the conventions. Only when they are aware of the risks will they be equipped to choose in the case of each encounter, between the short-term gains of compliance and the possible long-term gains from using "oppositional discourse."

In Part 4, there is a return to larger units of communicative interaction. The chapters by Saville-Troike (The Ethnography of Communication ) and by Cohen (Speech Acts) are essential undergirdings what has come to be known as Communicative Language Teaching.(CLT) The understanding of the basic concepts, principles and methods of research these chapters make possible could lead to a more sophisticated understanding of CLT and place teachers in a better position to develop their learners' skills as effective intercommunicators. 
The final chapter "Literacy and Literacies" by Sandra McKay is a coherent and succinct account of the complex relationships between literacy and its cultural and social context, which draws on a wide range of research. Though fairly short, the chapter addresses the central issues in a sophisticated and challenging way.

South African language teachers require a thorough grounding in and understanding of sociolinguistics. This text should be on the list of prescribed reading.

\section{E Ridge}

University of Stellenbosch 